\title{
On the Extensometer Whose Magnifier is a Zollner Suspension Type Tiltmeter, and the Observation of the Earth's Strains by Means of the Instruments
}

\author{
Izuo OzaWA $(*)$
}

Ricevuto i] 30 Magrgio 1965

\begin{abstract}
Sumyar. - In order to observe the gromnd-strain due to the tide generating force of the earth, it is necessary to record measurable the linear strains, which are as large as $10^{-10}$. For that purpose, it should not only make longer the base line on the ground, but also magnify the relative displacement of the both edge-points of the base line extremelr. A new type of highly sensitive extensometer of which magnifier is a Zölner suspension type tiltmeter is devised. In the mechanism of the extensometer, a superinvar rod whose the length is constant, is put parallel with the base line, and an edge of the rod is fixed on one edge of the line so that the relative displacement of the unfixed edge of the rod and the other edge of the line may be transformed into the inclination of the support of the Zölner pendulum. Conseguently, the pendulum of the tiltmeter rotates magniloquently. And also the rotational angle of the pendulum is enlarged and recorded with an optical lever on a photographic printing paper. The extensometer has a sensitivity in the order that is higher than the formerly used one, and the sensitivity is able to be perfectly controlled at will. As the sensitivity to the linear strain is more than 100 times as large as that of the extensometer as to the ground-tilting, the influence of the tilting may be neglected.

The linear strains of the eartli's surface in earth ticle are observed with this extensometer at Osakayama Observatory, and are obtained the analyzed values that are subtracted the influence of the ground-tilting. in four directions $\mathrm{N}-\mathrm{S}$, E-W, $s \quad 38^{\circ} \mathrm{W}$ and $\& 52^{\circ} \mathrm{E}$. Then, the earth-tidal constants $h-3 l, h$ and $l$ are obtained as $0.440,0.599$ and 0.053 respectively. And also the records (of the ground-strain) which are observed with new type extensometer are compared with them which are observed with other types'. In these records, the interesting phenomena which are generated within a short hour, are found.
\end{abstract}

(*) Geophricical Institute of Kyoto University. 
Risssuxto. - Allo scopo di osservare la deformazione della crosta della terra dovuta alla forza generatrice delle maree terrestri è necessario registrare le sollecitazioni lineari misurabili, dellordine di $10^{-10}$. A tale scopo, non soltanto si leve allungare di più la linea di base sul terreno, ma anche aumentare grandemente il relativo spostamento di ambedue i punti estremi del piano di base. E stato ideato un nuovo tipo di estensimetro ad alta sensibilità il cui amplificatore è un clinometro Zöllner di tipo a sospensione. Nel meccanismo dell'estensimetro un'asta di superinvar, la cui lunghezza è costante, è posta parallelamente al piano di base; un estremo dell'asta è fissato in modo che lo spostamento relativo dell'estremo non fisso dell'asta rispetto all'estremo del piano di base, possa essere trasformato in una inclinazione del supporto del pendolo Züllner. Di conseguenza, il pendolo del clinometro ruota in modo accentuato; ne risulta ingrandito anche l'angrolo di rotazione del pendolo che viene registrato con sistema ottico su carta fotografica. L'estensimetro ha una sensibilità maggiore di quello usato precedentemente, e la sensibilità può essere controllata a volontà. Siccome la sensibilità alla sollecitazione lineare è 100 volte maggiore di quella dell'estensimetro rispetto alla deformazione del terreno, l'influenza di quest'ultima può essere trascurata.

Le sollecitazioni lineari della superficie della terra nella marea terrestre vengono osservate con questo estensimetro presso l'Osservatorio Osakayama: dai valori analizzati ottenuti si sottrae l'influenza della deformazione del terreno, nelle quattro direzioni N-S, E-W, S $39^{\circ} \mathrm{W}, \mathrm{S} 52^{\circ}$ E. Le costanti della marea terrestre $h-3 l, h$ ed $l$ sono $0.440,0.599$ e 0.053 rispettivamente. Inoltre le registrazioni della sollecitazione del terreno che sono osservate col nuovo tipo di estensimetro, sono confrontate con quelle osser. vate con altri tipi e mettono in evidenza interessanti fenomeni che avvenrono perfino nel termine di un'ora.

\section{1) Ixtroductions.}

In order to observe the strainnings with extensometers for the studies of foreknowledge of the ontbreaks of the earthquakes ( $\left.{ }^{1}\right)$ and one of earth's free oscillations $\left({ }^{2}\right)$, it is necessary to make use of the extensometers whose orders of their sensitivities are $10^{-10}$ per millimeter on their records. One of the method to make them highly sensitive is to make their spans longer. It is, however difficult to make the span of the extensometer longer unrestictedly, because it is restricted by the conditions of the observatory and the material of the instrument. Therefore we also should devise the method to amplify the relative displacement on both side of the base line of the extensometer. And the magnifier is necessary to be fit for continuous and long date's observations. The present author has devised the new type of the extensometer whose amplifier consists of Zöllner suspension type's horizontal pendulum. In this 
method, the relative displacement of the both edge points is transformed into the inclination of the rotational axis of the horizontal pendulum and then the rotational angle is magnified by the optical lever on the records. This method is so excellent that we have nice observations of the crustal strains as the earth-tide, earth's free oscillation and crustal movements.

\section{2) INSTRUMFNTs.}

This new type's extensometer consists of three parts, the part of the standard scale, the one of the magnifier (enlarger) of the relative displacement and the one of the recording.

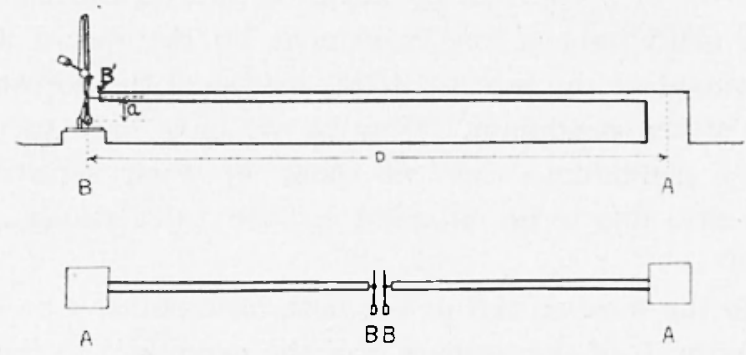

Fig. 1

The stundard scale $(P)$ ronsists of rods, about $1 \mathrm{~cm}$. diameter or pipes of about $3 \mathrm{~cm}$ in diameter, which are made of super-invar. The one edge of the scale is fixed on the base point $(A)$ to observe the relative displacements in the direction of the scale between the other edge of the scale and the other close base point on the ground. In some case, the fixed edge micro-adjuster, but this adjuster is included in the magnifier part in the improved type. The standard scale is set horizontally in the horizontal component and is set vertically in the vertical one. The magnifier part consists of the tiltmeter of Zöllner suspension type and the micro-adjustor of the interval between the unfixed edge of the satle and the joint of its tiltmeter on the base $B$ (Fig. 1).

The support $S$ of the tilmeter is about $20 \mathrm{~cm}$ in length and its below edge is supported with the pivot $C$ or with two sheets of the plate springs on the board $N$. The horizontal pendulum $H$ is suspended with stainless steel strings of $50 \mu$ in diameter from the upper edge of the support $S$ and the other point $J$ on the board $N$. The support $S$ and the 
unfixed adge $B^{\prime}$ of the scale is connected with the plate spring $E$. The distance between the fulcrum $C$ and the connecting point of $E$ is about $3 \mathrm{~cm}(2-5 \mathrm{~cm})$. The relative displacement between the unfixed edge $B^{\prime}$ and $B$ or $C$ is transformed into the inclination of the support $s$ then the horizontal pendulum is rotated magniloquently. The rotation of the pendulum is enlarged with the optical beam and the reflecting mirror fixed on the pendulum. The weight of the pendulum is about 15 gerams and the length of its equivalent simple pendulum is about $5.0 \mathrm{~cm}$. The period of the pendulum is adjusted with the horizontal movement of the suspension point $J$ as in Fig. $2^{\prime}$ or the tilting of the board $N$ as Fig. 2 and is able to prolong till about twenty seconds easily and to make the desired period. The pendulum has a weak damper of oil or magnet: (the ereater part of them has an oil damper). The fundamental measurement of its sensitivity is performed by means of the measuring the relation between the magnitude of the movement on the record and the one of the adjustment of the interval $\left(B B^{\prime}\right)$ by use of the adjuster $G^{\prime}$ at the fixed period of the pendulum. Usually, we have only to measure the periods of the pendulums, then we check up their sensitivities. The sensitivity is also able to be obtained by the calculations as following Fig. 2, Fig. 2'.

Let $D$ be the interval $A B$ of the both base point, $a$ be the ristance from the fulcrum $C$ of the support $S$ of the pendulum to the comnecting point $E$ of the support and the seale and $e$ be the change of the mean of the linear strain along $A B$. Then the tilting angle $d$ of the support is given as

$$
\phi=\frac{D}{a} e
$$

and the rotational angle $\vartheta$ of the horizontal pendulum is given as

$$
\vartheta=\frac{T^{2} g}{4 \pi^{2} l^{\prime}} \dot{\rho}=\frac{T^{2} g D e}{4 \pi^{2} l^{\prime} a}
$$

where $T$ is the period of the pendulum, $l^{\prime}$ is the length of the equivalent simple pendulum and $g$ is the acceleration of the gravity.

Using the optical lever of $L$ in length, the magnitude $y$ of the change on the recording paper is given as

$$
y=2 L \vartheta=\frac{L g T^{2} D_{e}}{2 \pi^{2} l^{\prime} a} .
$$


Then the sensitivity $S$ of the extensometer is expressed as

$$
S=\frac{e}{y}=\frac{2 \pi^{2} l^{\prime} a}{\lg D T^{2}}
$$

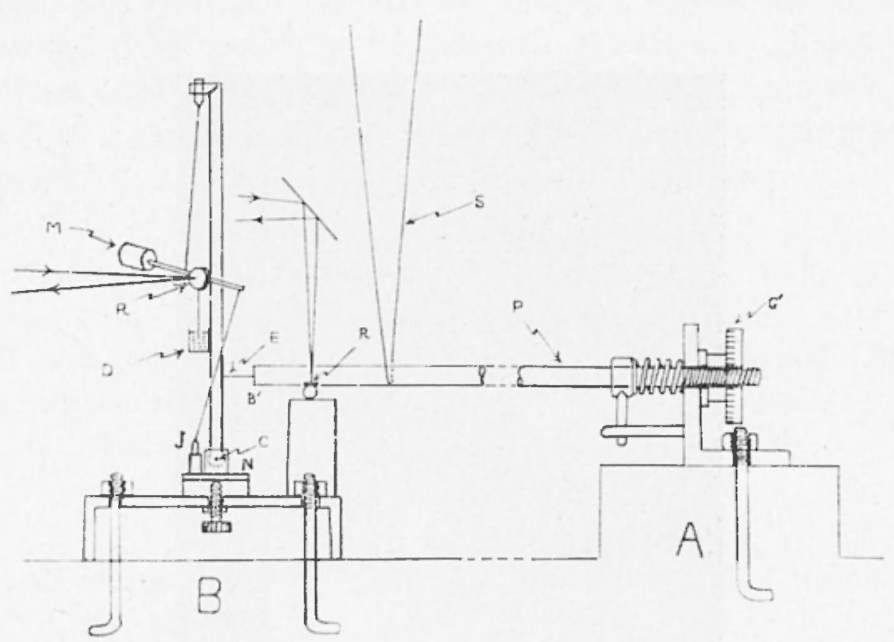

Fig. 2
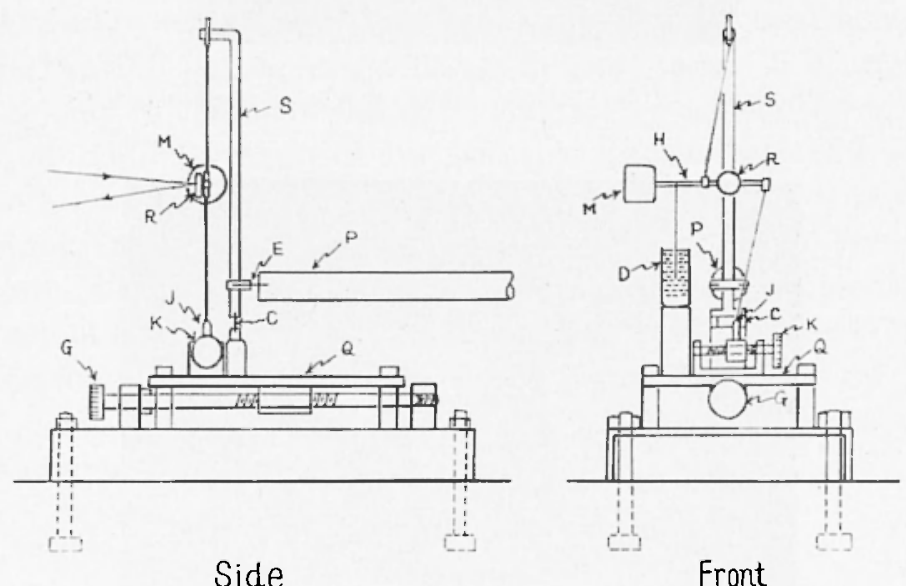

Fig. $2^{\prime}$ - The sketch of Amplifier Part of the Extensometer. $O$ is the support of the Pendulum, $D$ is the Damper, $E$ is the Connector, $G$ is the Span-Adjuster, $I I$ is the IIorizontal Pendulum, $K$ is the Period-Adjuster. $P$ is the Rod Scale, $Q$ is the Sliding Plate, $R$ is the Reflectiong Mirror and $s$ is the support of the Pendulum. 
Calculating the sensitivity by use of actual dimensions of the instruments are expressed as $l^{\prime}=5.0 \mathrm{~cm}, a=3.5 \mathrm{~cm}, L=200 \mathrm{~cm}$, $D=10 \mathrm{~cm}, P=10 \mathrm{sec}$, and formula [4], the change of $1 \mathrm{~mm}$ on the recording paper is equivalent to $1.76 \times 10^{-9}$ in the linear strain of the crust.

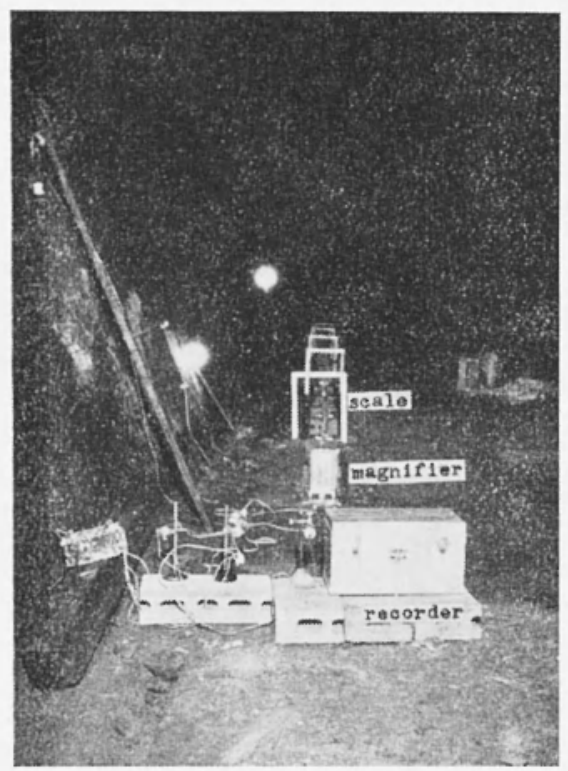

Photo ] - The Whole Tiew of the Extensometer

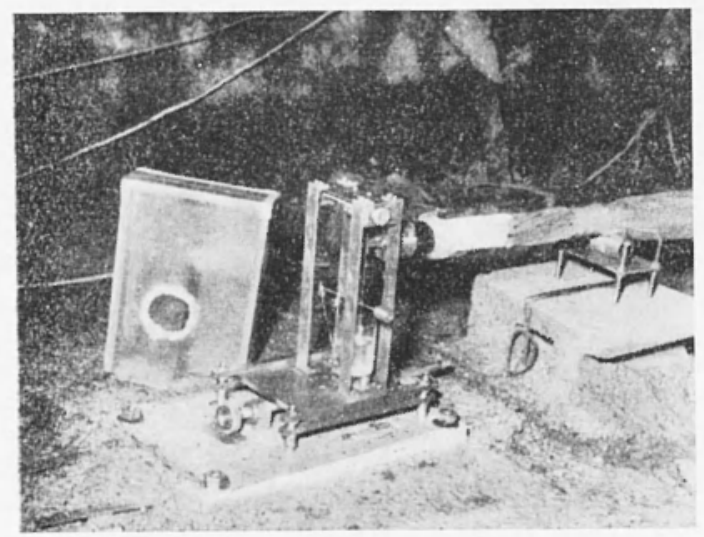

Photo la - The Magnifier Part of the Extensometer. This type is equipment with the vertical pendulum insteat of the inverted pendulum. 
Let the period $T$ be 20 sec, then $S$ is $4.4 \times 10^{-10}$ per one millimeter on the records. Measuring the changes till the dimension of 0.1 millimeter on the records, we are able to distinguish them till the order of $10^{-10}$ in the changings of the linear strains. We have obtained good agreements between the sensitivities obtained experimentally and the ones calculated by use of the formula [4]. We have to consider the effects of the inclinations of the ground because the amplifier consists of tiltmeter. Let $\varphi$ be the tilting of the ground. Then, the tilting $(\dot{\phi})$ of the support of the pendulum of the magnifier is given as

$$
\phi=\frac{D e}{a}+\varphi
$$

Let $e_{o} / \varphi_{0}$ be the specific ratio between $e$ and $\varphi$ when the first term is equal to the second in the formula [5]. Then we have

$$
\frac{e_{o}}{\varphi_{o}}=\frac{a}{D} .
$$

In actual case, $a<4 \mathrm{~cm}$. and $D>400 \mathrm{~cm}$. Then the magnitude of $e_{0} / \varphi_{0}$ is larger than 100 .

Therefore, if the length of the extensometer larger than is longer than four meters, the magnification of the earth's strain is 100 times of the one of the tilt; the longer the length of the extensometer is, the less the noise caused by earth's tilt we are able to make. We need not consider the effect caused by, the earth tiltings in usual cases. In a stricter case, we have only to eliminate the eflect due to the tiltings by use of the results of the observation of low sensitive tiltmeter at the near place. An another method is to combinate two extensometers whose amplifier parts are connected in the opposit sides respectively; these arrangement are shown in Fig. 1. In the vertical component of the extensometer, the construction of the amplifier is similar to the horizontal one. It seems that the methods of subtraction of the noise caused by earth-tilt is possible, but the cancelling method by the reversed instruments is comploated in usually.

\section{3) Observation.}

This type's extensometers are being used for the observations of the crustal deformations at Osakayama Observatory (Shiga Prefecture), Kishu Mine (Mie Prefecture) and Suhara Observatory (Wakayama 
Prefecture). In the present paper, the observations with the newly devised extensometers at Osakayama Observatory are reported. Osakayama Observatory is situated at $135^{\circ} 51^{\prime} .5$. E longitude and $34^{\circ} 59^{\prime} .6$. S latitude, and is in $\mathbf{1 0 0}$ meters above the sea level. And the Observatory is about $65 \mathrm{~km}$. to the nearest sea that is the Japan sea. The room of the observatory is about $\mathbf{1 0 0}$ meters under the ground. The amplitude of annual variation is $0.4^{\circ} \mathrm{C}$ and the one of the daily variation is less than $0.01^{\circ} \mathrm{C}$. The newly devised extensometers have been set in the directions of East to West and North to South in 1958, and afterward nine components of the extensometer have been set in Osakayama Observatory. The study of the comparison between the observations by the extensometers situated newly and the ones by the extensoneters set formerly.

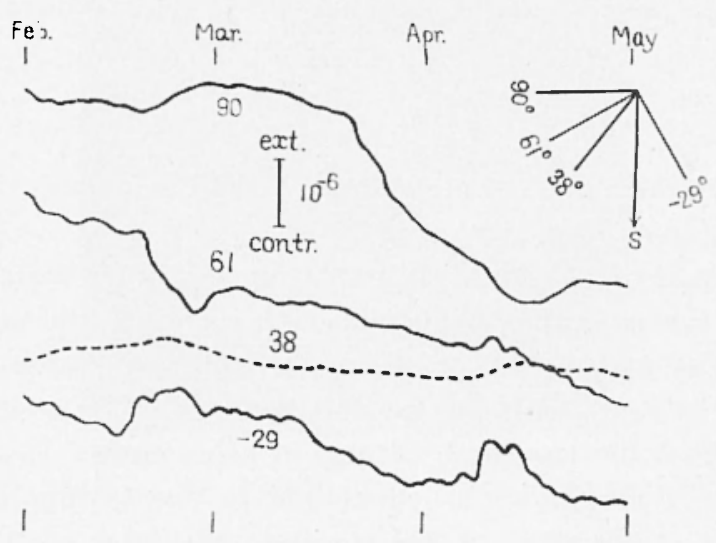

Figr. 3

The sensitivities of the instruments are adjusted to the magnitude of the seasonal change in the routine observations, and usually keeps up ample scope to ability of more precise observations for the special time.

Photo 1 shows the $E-W$ and $N^{\top}-S$ components of these instruments.

Fig. 3 shows the comparison of the seasonal changes which are observed with newly devised and old types $\left(^{3}\right)\left({ }^{1}\right)$ extensometers in the period from February to April in 1959; when there are many perturbations. The numerical signs on the curves show azimuths (measured from north in degrees) of the observing linear strains; curves 90 and 0 are the strainning with the newly devised types of extensometers along the directions of $E$-W and $N$-S, curve 61 is the one with the extensometer which 
consists of the combination of the horizontally slackening wire and galvanometer of the torsional wire, curve 29 is one of Sassa type's extensometer which consists of the vertically slackening wire and tri-fillatr suspension type pendulum and curve 38 is one of the rod and roller type's. As the observing directions are various, the forms of their changes are also various, but their absolute magnitude are almost equal and happened at the same times.

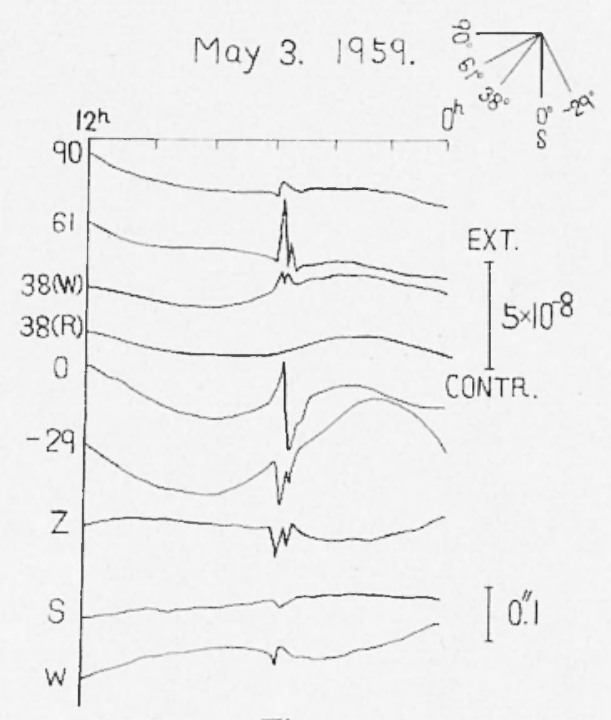

Fig. 4

Fig. 4 shows the sudden changes of the linear strains observed with various type's extensometers in the various directions, and the ground tiltings observed with the horizontal pendulum type's tiltmeters: 38 $(W)$ is the record by Sassa type's extensometer and $38(R)$ is one of the roller type's one, $Z$ is one of the vertical component of the extensometer, $S$ and $W$ is the one of south and west components of the ground-tilt, and others are the same as them in Fig. 3. From these changes, it seems that voller type extensometer does not record such changes because the roller of the amplifier has some frictions or the limit of linearity of the sensitivity is worse. The form of the short period's change in curve 90 looks like the one of curve $W$, but the long periods one does not. And also the one of 0 does not look like the one of $S$. From this fact and the result of formula [5], we understand that the perturbations in curve 0 and 90 , are not the effects of the ground tiltings. 


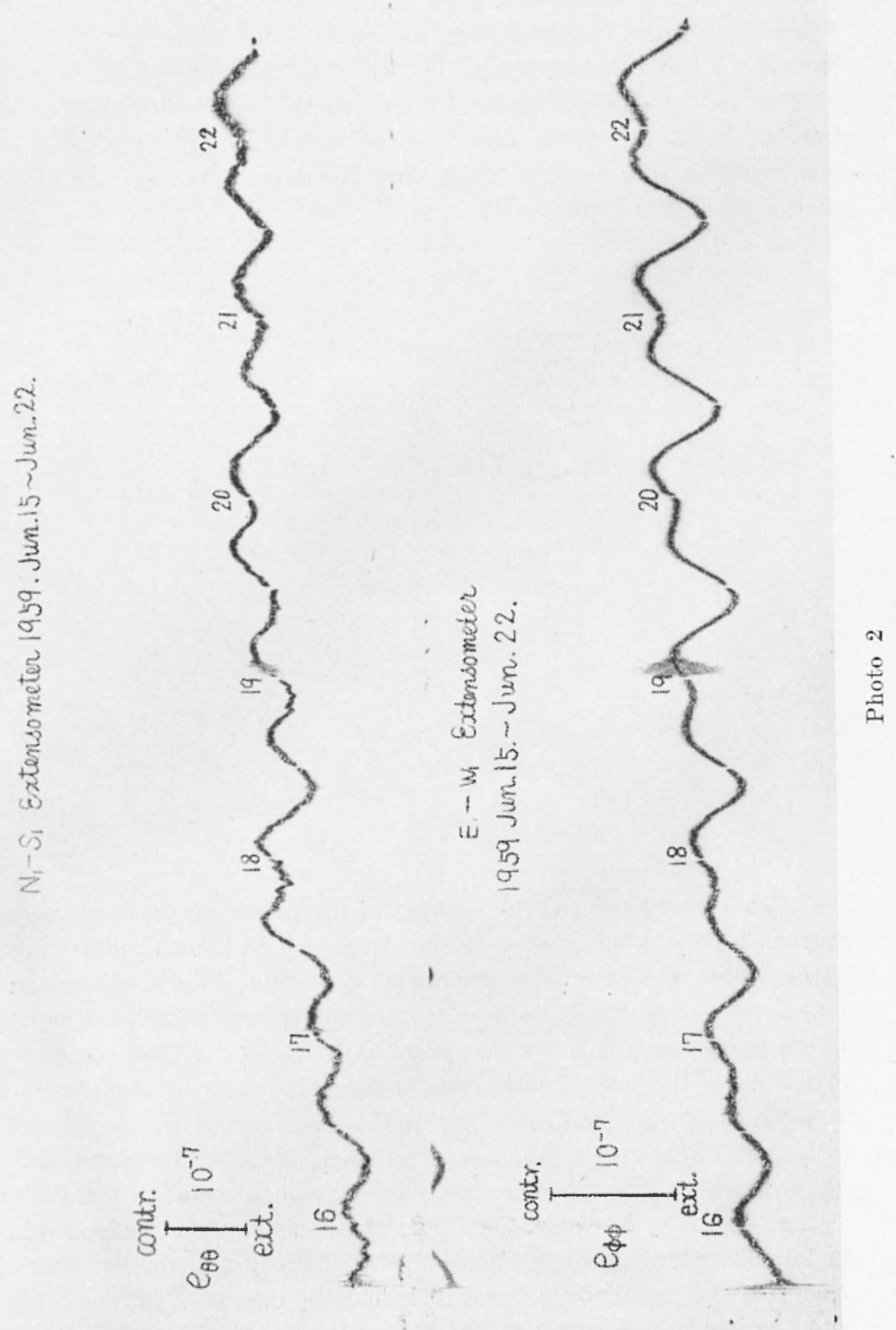




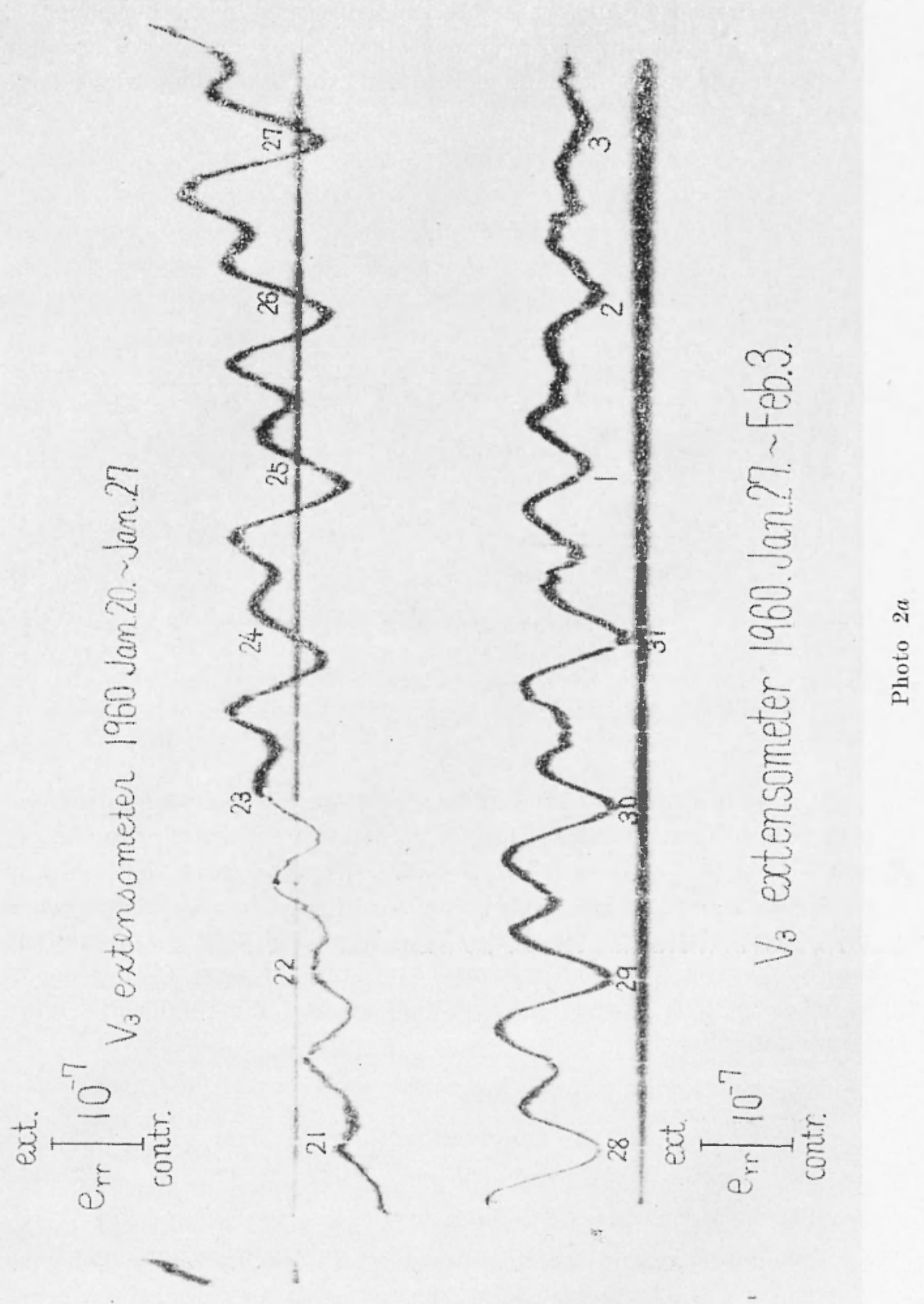


The distributions of the strain due to this perturbation, is solved as the quadrant-type and these question is discussed in another paper $\left({ }^{5}\right)$. It goes without saying that the newly devised extensometers are able to observe the micro strainning, less than the other ones which have been made till now.

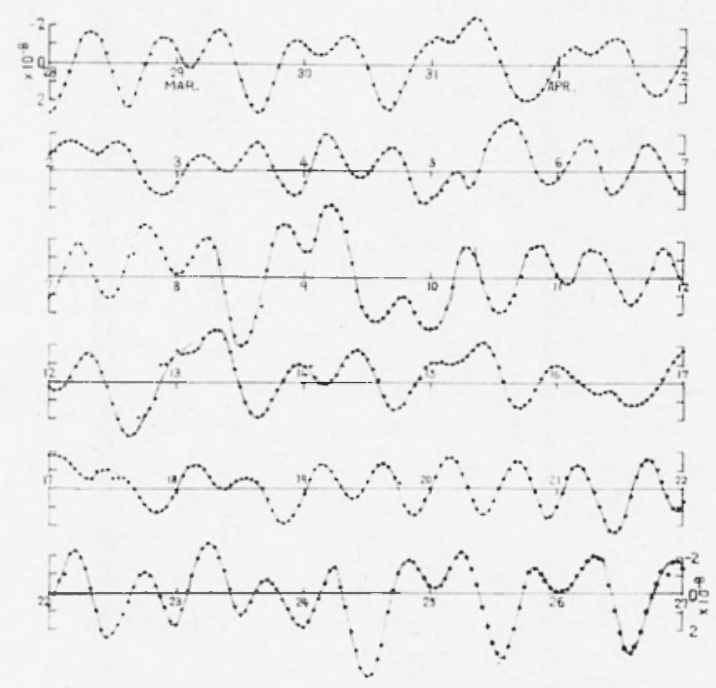

Fig. 5

Let us measure first the hourly values on the observed record and then subtract the rumning means of 25 hours of the series of the hourly means from the every measuring value. Then we have the series of the hourly means which consists mainly of the tidal variations and show the variations of the period from Mareh 281959 to April 261959 in Fig. 5. Next we calculated tidal constants $M_{2}$ and $O_{1}$, by means of improved T.I. method (Darwin-method) and the results are shown in the following.

The Observatory: Osakayama

The Direction of the Observation: Eist to West

The Length of the Span: $530 \mathrm{~cm}$.

The Period of the Analysis I:

The Tensitivity of the Instruments: $1.81 \times 10^{-8} / \mathrm{mm}(T=5,08 \mathrm{sec}$.$) ,$

The Analyzed Values: $M_{2}=0.632 \times 10^{-8} \cos \left(2 \mathrm{t}-4.6^{\circ}\right)$.

$$
O_{1}=0.672 \times 10^{-8} \cos \left(\mathrm{t}-22.0^{\circ}\right) \text {. }
$$


The Period of the Analysis II:

The Sensitivity of the Instruments: $0.53 \times 10^{-8} / \mathrm{mm}\left(T^{\prime}=8.6 \mathrm{sec}\right.$.).

The Analyzed Values: $M_{2}=0.758 \times 10^{-8} \cos \left(2 \mathrm{t}-359.7^{\circ}\right)$, $O_{1}=0.735 \times 10^{-8} \cos \left(\mathrm{t}-16.3^{\circ}\right)$.

The values obtained above contain a little noise caused by the tidal tiltings, which had been analyzed by use of the tilting's observations with horizontal pendulum type tiltmeters in the period from January, 1948 to February, 1949 at Osakayama. The $M_{2}$ and $O_{1}$-components of this tidal tilt in the prime vertical direction are expressed as

$M_{2}: 0.0042^{\prime \prime} \times \cos \left(2 \mathrm{t}-70^{\circ}\right), O_{1}: 0.0007^{\prime \prime} \times \cos \left(\mathrm{t}-218^{\circ}\right)$ in west-tilt, $M_{2}: 0.0028^{\prime \prime} \times \cos \left(2 \mathrm{t}-230^{\circ}\right), O_{1}: 0.0067^{\prime \prime} \times \cos \left(\mathrm{t}-220^{\circ}\right)$ in north-tilt.

As the dimension of $a / D$ of the extensometer above mentioned is 0.0070 , the noises caused by the both components of the west tidal tilt are given as

$$
\begin{aligned}
& M_{2}: 0.014 \times 18^{-8} \cos \left(2 \mathrm{t}--70^{\circ}\right), \\
& O_{1}: 0.003 \times 10^{-8} \cos \left(\mathrm{t}-218^{\circ}\right) .
\end{aligned}
$$

Subtrating these noise from the analyzed values of the extensometer, the mean values of the tidal component of the linear strains in the period I and II are given as

$$
\begin{aligned}
& M_{2}: 0.69 \times 10^{-8} \cos \left(21-0.9^{\circ}\right), \\
& O_{1}: 0.70 \times 10^{-8} \cos \left(t-19.1^{\circ}\right) .
\end{aligned}
$$

By the sime method, the more precise observations are performed afterward with the higher sensitivity and the longer periods. Now, these results are shown in the Table 1 . The values of $142^{\circ}$ and $38^{\circ}$ have been obtained by use of every 30 minutes' levels of the strain curves ${ }^{6}$ ).

In Table 1, the numerals in parenthesis are the uncorrected values from which the tilting effects are not subtracted.

If the ratio $h / l$ is about 0.1 , which is obtained afterward as $h / l=$ $11.1\left({ }^{7}\right)$, where $h$ and $l$ are Love's $\left({ }^{8}\right)$ and Shida's $\left({ }^{8}\right)$ numbers respectively; the amplitude of the diumal component of the tidal stmin is largest in the direction of the East to West and the one of the semi-diurnal component is largest in the one of the South to North. And also the amplitude of $O_{1}$-component is larger than the one of $H_{2}$-component. And so these relations are satisfied nearly in the Photo 1 and Table 1 , 


\begin{tabular}{|c|c|c|c|c|c|c|c|c|c|c|c|c|c|c|}
\hline \multirow{2}{*}{  } & 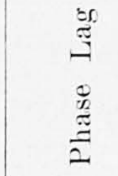 & & $\begin{array}{l}\text { o. } \\
\stackrel{\circ}{0} \\
\text { d. }\end{array}$ & $\overrightarrow{\text { ลิ่ }}$ & $\begin{array}{l}\widehat{\vartheta} \\
\stackrel{0}{\varrho} \\
\stackrel{\varrho}{*}\end{array}$ & $\stackrel{+}{0}$ & $\begin{array}{l}18 \\
\dot{\circ}\end{array}$ & & $\stackrel{\infty}{\infty}$ & & & & & \\
\hline & & $\stackrel{\infty}{0}$ & $\begin{array}{l}\text { â } \\
\stackrel{5}{0} \\
\stackrel{0}{e}\end{array}$ & $\begin{array}{l}10 \\
\stackrel{10}{0} \\
\stackrel{0}{0}\end{array}$ & 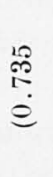 & $\begin{array}{l}\hat{n} \\
\dot{1} \\
0\end{array}$ & $\begin{array}{l}\stackrel{8}{0} \\
\stackrel{0}{0}\end{array}$ & & $\begin{array}{l}\text { O̊t. } \\
\stackrel{0}{0} \\
0\end{array}$ & & & & & \\
\hline \multirow{2}{*}{ 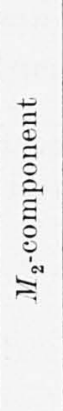 } &  & & $\begin{array}{l}\widehat{6} \\
\dot{0} \\
\dot{+}\end{array}$ & $\begin{array}{l}\mathscr{0} \\
\infty \\
\infty \\
i \infty \\
\infty\end{array}$ & $\begin{array}{l}\text { I } \\
\stackrel{8}{8} \\
\stackrel{8}{0}\end{array}$ & $\stackrel{0}{0}$ & 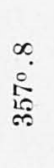 & & $\begin{array}{l}\stackrel{9}{0} \\
\stackrel{0}{0}\end{array}$ & & $\begin{array}{l}\theta: \\
\dot{8}\end{array}$ & & $\begin{array}{l}0 . \\
\dot{0}\end{array}$ & \\
\hline & 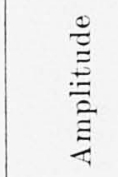 & $\frac{\infty}{0}$ & 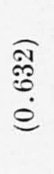 & $\begin{array}{l}\text { F } \\
\text { : } \\
\stackrel{0}{0} \\
0\end{array}$ & $\begin{array}{l}\widehat{\alpha} \\
19 \\
\stackrel{1}{0} \\
0 \\
0\end{array}$ & $\begin{array}{l}\text { is } \\
\stackrel{2}{0} \\
0\end{array}$ & $\begin{array}{l}\infty \\
\infty \\
\infty \\
0\end{array}$ & & $\stackrel{\overbrace{}]}{\stackrel{\oplus}{0}}$ & & $\stackrel{\Re}{\bullet}$ & & $\begin{array}{l}+ \\
0 \\
+ \\
0 \\
0\end{array}$ & \\
\hline &  & 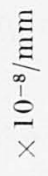 & $\stackrel{\infty}{\infty}$ & & $\begin{array}{l}\text { i⿱⺈ } \\
0 \\
0\end{array}$ & & 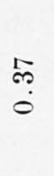 & & $\begin{array}{l}10 \\
0 \\
0\end{array}$ & & $\begin{array}{l}\stackrel{H}{0} \\
\dot{0} \\
0\end{array}$ & & 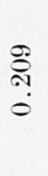 & \\
\hline & 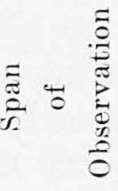 & $\Xi$ & $\begin{array}{l}\Re \\
10\end{array}$ & & $\widehat{\alpha}$ & & $\hat{\approx}$ & & $\stackrel{0}{0}$ & & $\stackrel{0}{\dot{\theta}}$ & & $\begin{array}{l}0 \\
\stackrel{0}{0}\end{array}$ & \\
\hline & 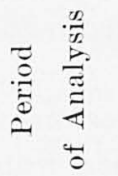 & & 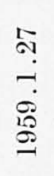 & $\begin{array}{l}\text { â } \\
\text { a } \\
1 \\
1\end{array}$ & 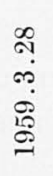 & $\begin{array}{l}\stackrel{0}{*} \\
\stackrel{+}{+}\end{array}$ & 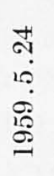 & $\begin{array}{c}\stackrel{9}{*} \\
\infty \\
1\end{array}$ & 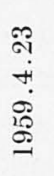 & $\stackrel{\text { กิ }}{\stackrel{N}{1}}$ & 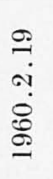 & 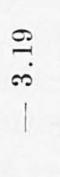 & 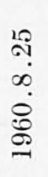 & $\begin{array}{c}\Re \\
\stackrel{9}{0} \\
\dot{0}\end{array}$ \\
\hline & 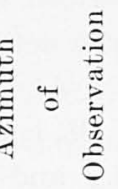 & & 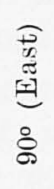 & & $\hat{\approx}$ & & $\Rightarrow$ & & 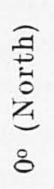 & &  & & $\begin{array}{l}\widehat{B} \\
0 \\
\infty \\
0 \\
0 \\
0 \\
0 \\
\infty \\
\infty \\
0\end{array}$ & \\
\hline
\end{tabular}


which show the diurnal components are remarkable in the $E-W$ component but are little in $N-S$ component.

Let $W_{2}$ be the tide-generating potential which is a spherical solid harmonic of $2^{\text {nd }}$ order, $F(r)$ and $G(r)$ be the functions of the distance $r$ from the earth's center only. Then the radial, colatitudinal and longitudinal displacements, $U_{r}, U_{\theta}$ and $U_{+}$respectively, are able to expressed as $\left({ }^{10}\right)$,

$$
\left\{\begin{array}{l}
U_{r}=\frac{2 F(r)+G(r) r^{2}}{r} W_{2} \\
U_{0}=\frac{F(r)}{r} \cdot \frac{\partial W_{2}}{\partial \theta} \\
U_{r}^{\prime}=\frac{F(r)}{r \sin \theta} \cdot \frac{\partial W_{2}}{\partial \phi}
\end{array}\right.
$$

From [7] and the formulas of strain elements, we have the prime vertical component $e_{\phi \phi}$ and the areal dilatation of the tidal strain $\Sigma$ as follows $\left({ }^{11}\right)\left({ }^{7}\right)$

$$
\left\{\begin{array}{l}
e \phi \phi=G(r) W_{2} \text { in diurnal component, } \\
\Sigma=e{ }_{2} \phi+e \theta \theta=2(h-3 l)-\frac{W_{2}}{a g}
\end{array}\right.
$$

From the mean vaunes weighted with observing spans and the period of analyses of $M_{2}$ components shown in Table 1 and formulas [8], we have following as

$$
\begin{aligned}
& G=0.74 \times 10^{-12} \\
& h-3 l=0.440
\end{aligned}
$$

The meanings of $G(r)$ are the $G=(h-2 l) / a g$ and one of the functions concerned with the radial displacement only, and so we are able to obtain from this relation as $h-2 l=0.493$, then $h=0.599$ and $l=0.053$.

Summarizing this paper, we have devised the experiment with the new type's extensometers whose sensitivities are able to be maintained in $10^{-10}$ per one millimeter on the record. Their sensitivities are able to be adjusted easily to any dimensions and at any time. We have been performing the much better observations than the ones of formerly used extensometers at Osakayama Observatory. From this observation we have obtained the values of $G(a)$ and $h-3 l$ directly. 


\section{ACKNOWLEDGEMENTS.}

The Anthor wishes to express his hearty thanks to Dr. K. Sassa and the late Tor. E. Nishinum, who are our teachers for their valuable advices. And he also wishes to express his many thanks to chief engineer K. Mlorimoto and others for their many helps.

\section{RIFliRENCLS}

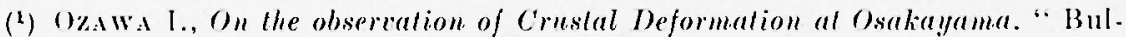
letin of the Disaster Prevention Research Institute of Kyoto Iniver. sity ${ }^{\prime}, 2,115-121$ (1949).

(2) Press F., Long-Period Waves and Free Oscillations of the Earth. - Ressearch in Geophysies", 2, 1.26 (1964).

(3) Ozawa 1., The Olservation of Tidal Fariation of the Linear Strain of the Earth. "Journal of the Geodetic Society of Japan ", 2, 54-58 (1955).

(4) Gzawa I., Comparative Obsermations of the Crustal Strain by IIeans of Wire-Types, and Rod-Type Extensomelers. "Iournal of the Geodetic Societ,y of Japan ", 7, 1-6 (1961).

$\left.{ }^{5}\right)$ Ozawa I., On the Obserwations of the Change of the Elastic Energ! in the Crust during the Renarkable Earthqualies. "Joumal of the Seismol. ogical society of Japan", 17, 222-232 (1964).

$\left({ }^{6}\right) 0 z a w a 1 .$, On the Mincing of the Reading-Lntervals in the Earth Tidal 1 malyses. "Journal of the Geodetic Society of Japan", 9, 14-21 (1963).

(7) Ozawa I., On the Observalions of the Earth Tide by Means of Extensometers in Ilorisontal Components, Disaster Prevention "Researrh Ins. titute Bulletin", 46, 1-15 (1961).

(") love d. E. 11., The Yielding of the Earth to Disfurbing Forces. "Proceeling of the Royal society of London", 82, 73-38 (1909).

(9) Snlwa P. and Matsurana II., Change of Plumb line Referred to the Ixis of the Earth as Found from the Result of the Luternational Latitude Observation. "Memoir of College of science and Lingineering", Kyoto Imperial l niversity. 4, 277-284 (1912).

(10) Takeuch1 II., On the Earth Tide of the Compressible Earth of Tariable Densily and Elasticity. "Transactions of the American Geophysical lnion “. 31. 651-689 (1950).

(11) 12AWa I.. Study on Elastic Strain of the Ground in Earth Tides. "Disaster Prevention Research Institute Bulletin", 15, 1-36 (1957). 